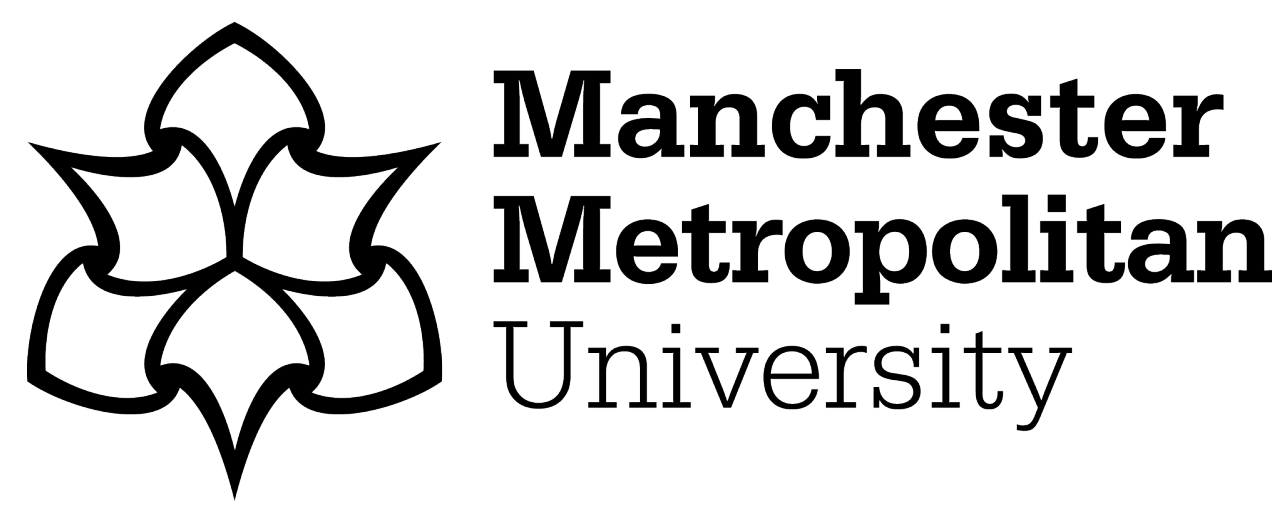

Inoue, Yuhei ORCID logoORCID: https://orcid.org/0000-0002-1983-6217, Funk, DC, Wann, DL, Yoshida, M and Nakazawa, M (2015) Team identification and postdisaster social well-being: The mediating role of social support. Group Dynamics, 19 (1). pp. 31-44. ISSN 1089-2699

Downloaded from: https://e-space.mmu.ac.uk/624284/

Version: Accepted Version

Publisher: American Psychological Association

DOI: https://doi.org/10.1037/gdn0000019

Please cite the published version 


\title{
Team Identification and Postdisaster Social Well-Being: \\ The Mediating Role of Social Support
}

\author{
Yuhei Inoue \\ University of Minnesota \\ Daniel C. Funk \\ Temple University \\ Daniel L. Wann \\ Murray State University \\ Masayuki Yoshida \\ Biwako Seikei Sport College \\ Makoto Nakazawa \\ University of Tsukuba
}

Author Note

Yuhei Inoue, School of Kinesiology, University of Minnesota; Daniel C. Funk, School of Tourism \& Hospitality Management, Temple University; Daniel L. Wann, Department of Psychology, Murray State University; Masayuki Yoshida, Department of Athletic Sports, Biwako Seikei Sport College; Makoto Nakazawa, Faculty of Health and Sport Sciences, University of Tsukuba.

The data used for this research were collected as part of the Spectator Survey Project conducted and funded by the Japanese Professional Soccer League (J. League) and the University of Tsukuba in 2012. We would like to thank the J. League for their support in this research.

Correspondence concerning this article should be addressed to Yuhei Inoue, School of Kinesiology, University of Minnesota, Minneapolis, MN 55455.

Email: yinoue@umn.edu

Please cite this article as: Inoue, Y., Funk, D.C., Wann, D.L., Yoshida, M., \& Nakazawa, M. (2015). Team identification and postdisaster social well-being: The mediating role of social support. Group Dynamics: Theory, Research, and Practice, 19(1), 31-44. http://dx.doi.org/10.1037/gdn0000019 


\begin{abstract}
This research confirms the relationship between team identification and social well-being in times of adversity, and demonstrates how the perception of two types of social supportinstrumental and emotional support - mediates this relationship. Analysis of data from spectators attending Japanese professional soccer games in the aftermath of the 2011 Great East Japan Earthquake identified a positive relationship between spectators' identification with a hometown team and postdisaster community cohesion, an indicator of social well-being. However, this relationship was partially mediated by the level of emotional support spectators perceived being provided by the team. In addition, perceptions of instrumental support from the team were unaffected by team identification, but positively predicted community cohesion. Our findings offer unique evidence for the ability of team identification to generate psychological benefits in the face of adversity, and advances the understanding of the mechanisms by which team identification leads to social well-being. This research further demonstrates that the mediating role of social support in the relationship between social identification and well-being may depend on the context of social identification under investigation as well as types of social support and well-being measured.
\end{abstract}

Keywords: team identification, social identification, social well-being, social support, disasters 
Team Identification and Postdisaster Social Well-Being:

The Mediating Role of Social Support

People's tendency to categorize themselves and others into a social group allows a major portion of their self-concept to be defined by that group's identity (Ashforth \& Mael, 1989; Mael \& Ashforth, 1992; Tajfel \& Turner, 1985). Extending the phenomenon of social identification to the spectator-sport team context, sport researchers have defined team identification as "a specific form of social identification that reflects a fan's psychological connection to a team" (Dimmock, Grove, \& Eklund, 2005, p. 76). Previous research has examined team identification predominantly from a business perspective such as its benefits for the team (Ahn, Suh, Lee, \& Pedersen, 2012; Kwon, Trail, \& James, 2007; Sutton, McDonald, Mime, \& Cimperman, 1997; Wakefield, 1995; Wu, Tsai, \& Hung, 2012) with limited but growing work exploring how spectators psychologically benefit by developing team identification (Wann, 2006; Wann, Dimmock, \& Grove, 2003; Wann, Waddill, Polk, \& Weaver, 2011). The latter work is meaningful because it is consistent with a substantial body of applied and social psychological research indicating that identification with a social group plays a central role in the maintenance and enhancement of one's well-being (Branscombe, Schmitt, \& Harvey, 1999; Haslam, Jetten, Postmes, \& Haslam, 2009; Haslam \& Reicher, 2006; Kellezi, Reicher, \& Cassidy, 2009).

The current research offers new insight on team identification by focusing on the psychological benefits that spectators obtain under stressful conditions. Specifically, while past work has tested the relationship between team identification and well-being in low stress times (e.g., Wann, et al., 2003, 2011), the confirmation of this relationship in times of adversity is required (Haslam, O’Brien, Jetten, Vormedal, \& Penna, 2005). Consequently, this research investigates the relationship between team identification and well-being in post-disaster 
situations where individuals are exposed to a high stress environment (Kaniasty, 2012).

Furthermore, to date, direct evidence with respect to reliable explanations of the mechanisms by which team identification affects spectators' well-being is lacking (Wann et al., 2011). In addition, although the integrated social identity model of stress (Haslam \& Reicher, 2006) proposes that social support mediates the effect of social identification on well-being, previous studies have reported mixed support for this proposition (Gleibs, Haslam, Haslam, \& Jones, 2011; Haslam et al., 2005; McNamara, Stevenson, \& Muldoon, 2013; Outten, Schmitt, Garcia, \& Branscombe, 2009). Therefore, this study seeks to advance the understanding of how team identification leads to well-being and further resolve inconsistent findings on the mediating role of social support in the relationship between social identification and well-being.

\section{Conceptual Framework and Hypotheses}

The research model presented in Figure 1 depicts the propositions of this research. Building on social identity theory (SIT; Tajfel \& Turner, 1979), individuals affected by a disaster were hypothesized to exhibit higher levels of postdisaster social well-being if their identification with a hometown sport team was more established. Furthermore, drawing from selfcategorization theory (SCT; Turner, Oakes, Haslam, \& McGarty, 1994) and disaster research on the role of social support (e.g., Kaniasty, 2012; Kaniasty \& Norris, 2000; Norris \& Kaniasty, 1996), we hypothesized that the effect of team identification on postdisaster well-being would be mediated by the extent to which individuals perceived receiving two types of social support instrumental and emotional support-from the sport team.

\section{Team identification and Social Well-being}

Positive psychological consequences of social identification have been well documented (Branscombe et al., 1999; Cruwys, Haslam, Dingle, Haslam, \& Jetten, 2014; Haslam et al., 2009; 
Mael \& Ashforth, 2001). Identification with a social group helps individuals increase their selfesteem, invest themselves in unselfish behaviors, have meaning in their lives, feel a sense of belonging, and raise their aspirations (Mael \& Ashforth, 2001). Social identification also helps alleviate the negative effect of prejudice associated with membership in a minority group, enabling its members to maintain their well-being (Branscombe et al., 1999). Furthermore, people who are highly identified with a valued social group are less likely to experience depression symptoms (Cruwys et al., 2014). According to SIT (Tajfel \& Turner, 1979), the social group's status can influence mental health when individuals define their identity based on group membership. Such individuals will receive psychological benefits (e.g., meaning, stability, enhanced well-being) from group membership, provided the group maintains a positive status (Haslam et al., 2009).

SIT further proposes that social identification has a stronger association with well-being at the collective level (i.e., social well-being) than at the personal level (i.e., psychological wellbeing; Rubin \& Hewstone, 1998; Wann, 2006). This perspective is due to the importance of social identity in groups that motivates people to maintain and enhance their well-being "as ingroup members, rather than as individuals" (Rubin \& Hewstone, 1998, p. 42). In addition, previous work (e.g., Leach et al., 2008) suggests that social identification captures one's sense of group solidarity, which has also been identified as an indicator of social well-being (Keyes, 1998; Kaniasty, 2012). Although the current study builds on the traditional approach that narrowly defines social identification as "a cognitive state of self-categorization" (Bergami \& Bagozzi, 2000, p. 557), the inclusion of solidarity in social identification by some work indicates a close connection between social identification and social well-being. Specifically, social wellbeing represents one's evaluation of well-being related to collective life, referring to the extent to 
which a person perceives themselves as a functioning member of his or her group or community (Breslow, 1972; Keyes, 1998). Social well-being is related to, but different from, psychological well-being, which is a "more private and personal criteria for evaluation of one's functioning" (Keyes \& Lopez, 2001, p. 48). Keyes's (1998) empirical analysis revealed significant but modest correlations between measures of social well-being and psychological well-being, demonstrating discriminant validity between the two types of well-being. With respect to associations with social identification, Branscombe et al. (1999) found that members' identification with a minority group correlated more strongly with indicators of their social well-being than with indicators of their psychological well-being.

Prior studies have examined the relationship between team identification and social wellbeing in a low stress situation (Branscombe \& Wann, 1991; Wann et al., 2003, 2011). Consistent with the propositions of SIT, these studies reported that team identification was significantly associated with social well-being in the form of enhanced collective self-esteem and social life satisfaction and decreased feelings of social isolation. In various contexts, disasters have also been shown to activate the function of social identification (Ai et al., 2011; Cox \& Perry, 2011; Drury, Cocking, \& Reicher, 2009). For example, an analysis of personal accounts of witnesses and survivors of the 2005 London bombings revealed that feelings of the shared danger from the disaster enhanced a sense of common identity in the crowd, which in turn encouraged them to engage in helping behavior (Drury et al., 2009). Therefore, the positive association between team identification and social well-being identified in a low stress situation would likely be extended to a high stress situation caused by a severe disaster. In particular, given that the majority of spectators of a sport team live in the geographic vicinity of where the team plays home games (Hunt, Bristol, \& Bashaw, 1999), spectators' identification with a hometown sport team is 
expected to be related to their social well-being as a member of its local community following a disaster.

The psychological mechanisms underlying the relationship between team identification and social well-being, however, have yet to be confirmed. Wann's (2006) team identificationsocial psychological health model asserted that spectators' identification with a local team helps establish social connections with other residents in their community. The establishment of social connections within the community should subsequently enhance the spectators' social well-being as a community member. Wann et al.'s (2011) examination of U.S. college students' identification with a university's sport team, however, did not reveal strong empirical support for this assertion. Specifically, social connections with other local fans failed to predict social wellbeing, although team identification had a significant association with both social connections and social well-being. This evidence suggests that another mechanism may be operating to mediate the effect of team identification on social well-being.

\section{Social Identification and Social Support}

The cognitive theory of psychological stress and coping (Folkman, Lazarus, Gruen, \& DeLongis, 1986) suggests that the effect of stressful events on well-being depends in part on the availability of coping resources. People can maintain their well-being even under a stressful situation if they perceive having substantial resources to cope with the situation. A major component of such coping resources is the level of social support people have from others (Kellezi et al., 2009). In various settings, such as a workplace (Haslam et al., 2005) and care homes (Gleibs et al., 2011), the perception of social support has been proposed to enhance one's well-being by increasing the capacity to cope with adversity. Psychological research on disasters has also examined the role of the perceptions of the availability and receipt of social support in 
postdisaster recovery (e.g., Kaniasty \& Norris, 2000; Norris \& Kaniasty, 1996). The research provided evidence for the relationship between the perception of received social support and postdisaster well-being (Kaniasty, 2012). Specifically, flood victims in Poland were found to exhibit a higher level of social well-being 20 months after the flood if they perceived receiving more social support from family, friends, and other social groups (Kaniasty, 2012). Based on this empirical finding, individuals who perceive receiving higher levels of social support from a hometown sport team would likely show higher levels of postdisaster social well-being.

The behavioral influence of social identification proposed by SCT (Turner et al., 1994) further explains the link between social identification and social support. Specifically, people are more likely to help another individual when they categorize themselves and the individual as members of the same social group (Haslam \& Reicher, 2006; Haslam et al., 2009; Levine, Prosser, Evans, \& Reicher, 2005). This helping behavior tendency affects the perception of social support, that is, "social support is more likely to be given, received, and interpreted in the spirit in which it is intended to the extent that those who...provide and receive that support perceive themselves to share a sense of social identity" (Haslam et al., 2009, p.11). Previous research has reported that various sport teams actively engaged in disaster relief efforts when their local communities were affected by disasters (Inoue \& Havard, 2014). If the propositions of SCT are applicable to this context, individuals who are more strongly identified with a hometown sport team would likely perceive the sport team as providing higher levels of social support.

\section{The Mediating Role of Social Support}

Collectively, the aforementioned discussion highlights the potential mediating role of social support in the relationship between team identification and postdisaster social well-being. 
This mediational proposition is supported by empirical evidence (Haslam et al., 2005) and the integrated social identity model of stress (Haslam \& Reicher, 2006). However, three recent studies have failed to find a mediating effect of social support (i.e., Gleibs et al., 2011; McNamara et al., 2013; Outten et al., 2009). A case study of residents in disadvantaged communities in Ireland reported that residents' perception of social support from their neighbors did not mediate the relationship between their community identification and psychological wellbeing (McNamara et al., 2013). Similarly, Outten et al. (2009) found no evidence that the relationship between African Americans' identification with their racial group and psychological well-being was mediated by the perceived availability of social support from the group.

This failure to confirm the mediating role of social support suggests that "the relationship between social identity, social support and well-being may vary across different group contexts" (McNamara et al., 2013, p. 398). Specifically, McNamara et al. (2013) and Outten et al. (2009) investigated the mediational role of social support in disadvantaged groups. Consistent with Branscombe et al. (1999), the findings of these two studies indicated that social identification with disadvantaged groups influences the perceived social support and well-being of group members. Both studies, however, did not reveal a significant association between social support and well-being in this context. The failure to support a linkage between social support and wellbeing may reflect the complexity of group dynamics in a disadvantaged group in which people seek to distance themselves from others engaging in anti-social behavior to avoid negative stereotypes associated with the group (MacNamara et al., 2013). This division in the group may lead socially responsible members to devalue social support from those considered to be antisocial, and vice versa. In addition, Gleibs et al.'s (2011) study examined how social identification and social support would influence well-being when people were assigned into a 
new social group (i.e., water club in a care home), reporting that social identification, not social support, served as the mediator. Based on their finding, it may be more appropriate to view social support as a predictor of social identification rather than an outcome in the early stage of group development. Taken together, the contexts of the previous studies suggest that in situations where social identification is more salient and not stigmatized, social support may emerge as a mediator.

Two additional points provide further insight into why the three studies noted above (Gleibs et al., 2011; McNamara et al., 2013; Outten et al., 2009) did not produce a mediating effect of social support. First, all three studies examined the role of social support in the relationship between social identification and indicators of psychological well-being rather than social well-being, which has been shown to have an association with both social identification and social support (Branscombe et al., 1999; Kaniasty, 2012; Rubin \& Hewstone, 1998; Wann, 2006). Therefore, measuring social well-being, instead of psychological well-being, may allow researchers to better understand the relationship among social identification, social support, and well-being.

Second, although both Gleibs et al. (2011) and McNamara et al. (2013) measured social support broadly, the literature has suggested that at least two different types of social support exist: instrumental support and emotional support (Adams, King, \& King, 1996; Carver, Scheier, \& Weintraub, 1989). Instrumental support refers to "tangible assistance aimed at solving problem" (Adams et al., 1996, p. 412). Emotional support refers to comfort and acceptance that assist people in reducing psychological stress from stressful events (Norris, Murphy, Kaniasty, Perilla, \& Ortis, 2001). Decomposing social support into these two types is important because previous evidence suggests that instrumental and emotional support differently affects well-being 
(Adams et al., 1996; Kaufmann \& Beehr, 1989). Based on this evidence, Outten et al. (2009) examined the mediating effect of instrumental support (named intragroup problem-focused options in their study) and emotional support (named intragroup emotional-focused options) separately, but found that neither of the two types mediated the relationship between social identification and well-being. Outten et al., however, suggested that this finding may be attributable to the fact that the study measured the perception of the availability, rather than the receipt of, social support. Consequently, decomposing social support into instrumental and emotional support and measuring the extent to which individuals perceived receiving each type of support may reveal the mediating role of social support.

Given the abovementioned discussion, we tested the mediating role of social support in the relationship between team identification and postdisaster well-being by (a) focusing on spectators' social well-being as the dependent variable and (b) measuring instrumental and emotional support separately. Our hypotheses are:

Hypothesis 1: Team identification would be positively related to postdisaster social wellbeing.

Hypothesis 2: The perception of the receipt of instrumental support from the hometown sport team would mediate the relationship between team identification and postdisaster social well-being.

Hypothesis 3: The perception of the receipt of emotional support from the hometown sport team would mediate the relationship between team identification and postdisaster social well-being.

\section{Method}

\section{Research Context}


Date were collected from spectators of teams belonging to a Japanese professional soccer league (i.e., J. League) in the aftermath of the Great East Japan Earthquake - the 9.0-magnitude earthquake occurred on March 11, 2011. This earthquake caused widespread damage to the eastern regions of the country and resulted in over 18,000 deaths and an estimated total economic loss of US\$210 billion (Guha-Sapir, Vos, Below, \& Ponserre, 2012). This particular setting was chosen because both the J. League and its individual teams engaged in substantial disaster relief efforts following the earthquake, including the league total of 1,856 different activities and approximately US\$8 million donations within one year following the earthquake (J. League, 2012a). Examples of disaster relief activities included those aimed to provide instrumental support, such as monetary and in-kind donations for residents in each club's hometown and participation in volunteer activities by players and team staff. In terms of emotional support, relief activities included players' visiting local evacuee shelters and schools and the operations of youth soccer clinics and other community events in severely affected areas (J. League, 2012a).

Data were collected at home games of three J. League teams - the Vegalta Sendai, the Kashima Antlers, and the Montedio Yamagata_-in October 2012. The timing of the data collection is consistent with past research on the impact of a natural disaster on social well-being (Kaniasty, 2012), and is appropriate for the current study given that victims of the Great East Japan Earthquake were reported to suffer from psychological distress even two years after the earthquake (Markus, 2013). All three teams are based in cities located in northeastern Japan, where the damage from the earthquake was the most severe. In addition, each of the three teams actively implemented the disaster relief efforts noted above in its hometown: the donation of about US\$36,000 and 186 separate relief activities by the Vegalta Sendai, the donation of about US\$680,000 and 87 activities by the Kashima Antlers, and the donation of about US\$62,000 and 
37 activities by the Monteido Yamagata within one year following the earthquake (J. League, 2012a).

\section{Participants and Procedure}

This study was conducted as part of a league-wide annual spectator survey. Japanese language questionnaires containing questions on spectators' demographics, event experience, and opinions on the hometown team were returned from 394 spectators at a Vegalta Sendai game, 412 spectators at a Kashima Antlers game, and 412 spectators at a Montedio Yamagata, resulting in a total sample of $1,218 .^{1}$

Of the 1,218 spectators, 893 who identified themselves as a fan of the hometown team and provided responses for all study variables were included in the final sample. Of the total sample, $60.8 \%$ of the respondents were male; their average age was 39.39 years $(S D=13.99)$; and they had an average of 9.16 years $(S D=5.76)$ of being a fan of the hometown team. A comparison of the study's sample with the demographic characteristics of all spectators responding to the spectator survey at home games of all J. League teams in the same year $(n=$ 16,645 ; percentage of male spectators $=62.8 \%$; mean age $=39.0$ years; J. League, $2012 \mathrm{~b}$ ) indicated that the current sample was representative of typical spectators of J. League games.

\section{Measures}

Measures used for this study included scales for team identification, the two types of social support, and postdisaster community cohesion to serve as an indicator of social wellbeing. Unless noted otherwise, these measures were developed in Japanese by the authors, and were translated into English for this paper by the first author who is a native Japanese speaker and holds a doctoral degree from a U.S. institution. 
Team identification. Team identification was operationalized as spectators' identification with the hometown sport team, measured with three items from Trail and James's (2001) scale ("I consider myself to be a real fan of the team," "being a fan of the team is very important to me," "I would be disappointed if I had to stop being a fan of the team"; $\alpha=.85$ ). The use of this scale is consistent with past studies on sport spectators (e.g., Yoshida, Gordon, Nakazawa, \& Biscaia, 2014). The response categories for the items ranged from 1 (strongly disagree) to 5 (strongly agree). In order to confirm the accuracy of the Japanese translation of this scale, back translation was conducted. In particular, the fourth author first translated the scale into Japanese. To test the equivalence between the original English and Japanese scales, the fifth author who is also Japanese and fluent in English conducted back-translation into English. Subsequently, a U.S.-born American citizen assessed differences in meaning between the original and back-translated scales, verifying that both scales reflect the same construct domain.

Instrumental support. Based on Adams et al.’s (1996) definition, a single item measuring spectators' perception of the level of instrumental support from the home team was developed: "Have you received any tangible assistance from the team's disaster relief activities?" The response categories for this item ranged from 1 (never) to 5 (many times). The use of the single item for instrumental support is consistent with Rossiter's (Bergkvist \& Rossiter, 2007; Rossiter, 2002) suggestion that a single-item measure is preferred over multi-item scales when the scope and definition of constructs are concrete, which applies to this variable.

Emotional support. As noted, emotional support refers to comfort and acceptance that help reduce psychological stress from a disaster (Norris et al., 2001). Based on this definition, three items to measure the extent to which respondents perceived having received emotional support from the hometown team were developed ("have you been comforted by the team's 
disaster relief activities?" "have you been reassured about the recovery from the earthquake because of the team's disaster relief activities?" "have you been relieved by the team's disaster relief activities?"; $\alpha=.89$ ). The response categories for these items ranged from 1 (never) to 5 (many times).

Postdisaster community cohesion. Based on Kaniasty (2012), a scale measuring the perceived sense of community cohesion following the earthquake was developed as an indicator of postdisaster social well-being. Community cohesion is defined as individuals' perceptions about the sense of community and existence of communal solidarity (Kaniasty, 2012). The use of community cohesion as a social well-being indicator is consistent with Keyes's (1998) conceptualization identifying social integration, which draws on the concept of collective cohesion, as a dimension of social well-being. This scale consisted of the following four items ( $\alpha$ $=.89$ ) developed based on Kaniasty's scale: "I think my neighbors have more trust in each another than they did before the earthquake," "I feel more strongly that I am a member of my community after the earthquake," "I feel that my neighbors have become more united since the earthquake," "I think that my neighbors are more kind to each other than they were before the earthquake." We developed these items rather than directly using Kaniasty's original scale to take into account cultural sensitivity. The response categories for the items ranged from 1 (strongly disagree) to 5 (strongly agree).

Control variables. Two dummy variables (i.e., Sendai, Kashima) were included to control for the sites of the data collection. Questions related to respondents' gender, age, and spectator experience (i.e., years of being a fan of the home team) were also used as control variables. In addition, given the potential that social well-being following a disaster may be influenced by the degree of exposure to the disaster (Kaniasty, 2012), the following two 
variables were measured. First, participants' level of material losses due to the earthquake was measured with a single item, "to what degree of material loss did you have from the earthquake?" The response categories for this item ranged from 1 (no damage) to 5 (enormous damage). Second, participants indicated their level of life threat due to the earthquake by answering the following item from Kaniasty (2012) on a 5-point scale ranging from 1 (did not feel at all) to 5 (felt enormously): "Did you ever feel like your life was in danger during the earthquake?" Finally, to control for the extent to which respondents perceived having received social support from other sources (e.g., family, friends, social groups) than the hometown team, respondents were asked to indicate their perception of the level of social support from other sources on a 5-point scale ranging from 1 (never) to 5 (many times).

Construct validly assessment for the multi-item scales. After the data collection phase, the construct validity of the three multi-item scales of team identification, emotional support, and postdisaster community cohesion were assessed through a confirmatory factor analysis (CFA) using Mplus 7.0. The maximum likelihood estimation with robust standard errors (MLR) was employed as an estimation method to address the potential violation of multivariate normality (Muthén \& Muthén, 1998-2012). The analysis supported the overall fit of the measurement model, $\mathrm{CFI}=.98, \mathrm{RMSEA}=.05, \mathrm{SRMR}=.02$. In addition, team identification had the construct reliability (CR) of .86 and the average variance extracted (AVE) of .67; emotional support had the CR of. 89 and the AVE of .68; and postdisaster community cohesion had the CR of .89 and the AVE of .73. All three scales exceeded the recommended level of .70 for CR and .50 for AVE, demonstrating convergent validity (Fornell \& Lacker, 1981; Hair, Anderson, Tatham, \& Black, 1998). Moreover, the AVE value of each scale was found to be greater than the square of 
its correlation with any others scales, supporting discriminant validity (Fornell \& Lacker, 1981). The results collectively provided evidence for the construct validity of the three scales.

\section{Analysis and Results}

\section{Descriptive Results}

Table 1 presents the descriptive statistics and correlations for the variables. With respect to the degree of exposure to the earthquake, the respondents' mean score on material losses (2.8) and life threats (4.0) exceeded the midpoints of the scales (2.5). Frequency analyses further revealed that $61.0 \%$ of the respondents reported at least some material losses, and $93.9 \%$ reported feeling a threat to life at least to some extent, by selecting the response of 3 or higher for each scale. These results suggested that the majority of the spectators included in the sample experienced substantial damage and threat from the disaster. Regarding the correlations, postdisaster community cohesion was significantly correlated with team identification $(r=.15, p$ $<.001)$, instrumental support $(r=.29, p<.001)$, and emotional support $(r=.49, p<.001)$. In addition, team identification was significantly correlated with emotional support $(r=.27, p$ $<.001)$, but had a nonsignificant correlation with instrumental support $(r=-.01, p=.64)$.

Furthermore, the correlation between instrumental support and emotional support was significant but moderate $(r=.33, p<.001)$, suggesting the discriminant validity of the two variables.

The correlation results were generally consistent with the hypotheses. The possibility of common method variance (CMV) contamination, however, exists due to the use of the same method of measurement (i.e., Likert scale). To address this potential issue, a partial correlation analysis explained by Lindell and Whitney (2001) was performed. For this analysis, the correlation between team identification and life threat $(r=.05)$ was used as the estimate of CMV because these two variables (a) had the smallest correlation value among all pairs of variables 
measured using a Likert scale and (b) were theoretically unrelated (i.e., it is unlikely that a spectator's degree of life threat due to the earthquake would be systematically explained by his or her level of identification with a hometown team or vice versa). This analysis revealed that all of the significant zero-order correlations indicated above remained significant $(p<.01)$ after the CMV adjustment, suggesting that CMV cannot account for the results (Lindell \& Whitney, 2001). ${ }^{2}$ Consequently, the study hypotheses were tested through regression analyses.

\section{Testing of Hypotheses}

To test the hypotheses, a regression analysis with Preacher and Hayes's (2008) bootstrapping approach was performed to allow for the simultaneous examination of multiple mediators. The regression model significantly explained postdisaster community cohesion, $R^{2}=$ $27, p<.001$. Specifically, of the control variables described above, age $(b=0.04, t=2.71, p$ $=.007)$ and life threat $(b=0.07, t=2.84, p=.005)$ positively predicted postdisaster community cohesion, while spectator experience $(b=-0.09, t=-2.18, p=.03)$ and Kashima (i.e., one of the two dummy variables for data collection sites; $b=-0.14, t=-2.43, p=.02$ ) had a negative association with the outcome. For Kashima, given the direction of the coefficient, the result indicated that the spectators of the Kashima Antlers reported lower postdisaster community cohesion than the spectators of the Montedio Yamagata (i.e., reference group). This finding that one's evaluation of community cohesion differs between communities is consistent with previous research (Buckner, 1988).

Moreover, controlling for the effects of these control variables, team identification had a significant positive total effect on postdisaster community cohesion $(b=0.12, t=4.30, p<.001)$. This result confirmed Hypothesis 1. Regarding the two mediators, team identification was positively associated with emotional support $(b=0.31, t=8.21, p<.001)$, but had a 
nonsignificant association with instrumental support $(b=-0.07, t=-1.64, p=.10)$. In addition, both instrumental support $(b=0.08, t=3.70, p<.001)$ and emotional support $(b=0.24, t=9.84$, $p<.001$ ) had a significant positive direct effect on postdisaster community cohesion. The analysis demonstrated that the direct effect of team identification on postdisaster community cohesion remained significant, but became weaker $(b=0.06, t=1.97, p=.049)$, when its indirect effects through instrumental and emotional support were taken into account. These results are shown in Figure 2.

Evidence to address Hypotheses 2 and 3 is presented in Table 2. This information presents the bootstrap estimates for the indirect effects of team identification on postdisaster community cohesion through instrumental and emotional support based on the bootstrap samples of 5,000. The confidence interval (CI) was set to $99 \%$ to provide conservative results. The mean estimate of the indirect effect through instrumental support was -0.01 and its $99 \%$ CI included zero $[-0.017,0.002]$; whereas the mean estimate of the indirect effect through emotional support was 0.07 and its $99 \%$ CI excluded zero [0.044, 0.114]. Taken together, these results suggest that emotional support, but not instrumental support, partially mediated the relationship between team identification and postdisaster community cohesion. Consequently, Hypothesis 2 was rejected, and Hypothesis 3 was supported.

\section{Testing of Reversed Mediation Models}

One alternative explanation for the relationship among social identification, social support, and well-being is that social identification mediates the relationship between social support and well-being (Gleibs et al., 2011). In the current research context, for example, it is possible that the perceived receipt of instrumental and emotional support would allow spectators to increase their identification with the hometown sport team; in turn, increased team 
identification would lead them to enhance their postdisaster community cohesion. To rule out this explanation, two reversed mediation models using Preacher and Hayes's (2008) bootstrapping approach were performed (bootstrap samples $=5,000, \mathrm{CI}=99 \%$ ). In the first model, team identification was specified as a mediator of the relationship between instrumental support and postdisaster community cohesion after controlling for emotional support and the other control variables. The analysis indicated that the direct effect of instrumental support on postdisaster community cohesion was significant $(b=0.08, t=3.70, p<.001)$, but its indirect effect through team identification was nonsignificant with the $99 \% \mathrm{CI}$ including zero $[-0.012$ to 0.001]. Similarly, in the second model, team identification was specified as a mediator of the relationship between emotional support and postdisaster community cohesion after controlling for instrumental support and the control variables. Emotional support had a significant direct effect on postdisaster community cohesion $(b=0.24, t=9.84, p<.001)$, but its indirect effect through team identification was nonsignificant, 99\% CI [-0.004, 0.034]. The collective results from the two models thus rejected the alternative explanation that team identification was a mediator for the relationship between each type of social support and postdisaster community cohesion.

\section{Discussion}

The results of this study indicate that individuals who report elevated levels of identification with a hometown sport team also have higher social well-being as indicated by the level of community cohesion in the aftermath of stressful events. Although previous studies have demonstrated the significant association between team identification and social well-being in low stress times (Branscombe \& Wann, 1991; Wann et al., 2003, 2011), confirming this association through the examination of spectators experiencing a highly stressful event adds new knowledge 
to the literature. In addition, the results of the mediation analysis suggest that highly identified spectators perceive receiving more emotional support from the team's disaster relief efforts. In turn, greater perceptions of emotional support help the spectators maintain higher levels of social well-being following adversity. The finding on the mediating role of emotional support contributes to team identification-social psychological health model (Wann, 2006) by demonstrating an alternative pathway by which team identification leads to social well-being. The current analysis also provides robust evidence for the integrated social identity model of stress by statistically controlling for CMV and reverse mediation, which were not addressed by the previous research supporting this model (Haslam et al., 2005).

Our results differ from previous findings (i.e., Gleibs et al., 2011; McNamara et al., 2013; Outten et al., 2009) that did not report a mediating effect of social support. The discrepancy can be explained by the research context where social identification was salient and unassociated with stigma-related group membership as well as the examination of social well-being and the two separate types of social support. As discussed in the development of the hypotheses, an investigation that (a) considers the context of social identification, (b) decomposes social support, and (c) focuses on social well-being may be advantageous to understanding how social support mediates the effect of social identification on well-being. The results also highlight the uniqueness of the spectator-sport team relationship that can generate high emotions and passions among spectators (Holt, 1995; Wann, Melnick, Russell, \& Pease, 2001). Specifically, as indicated by the relatively high mean values of team identification (4.4) and emotional support (3.5), the influence of the game situation may have contributed to the immediate salience of team identification while evoking emotional responses among spectators, strengthening the relationship between the two variables. 
Moreover, the results indicate that the perceived instrumental support from the team among spectators is not influenced by the level of team identification. One potential explanation for this finding is that this study examined the perception of instrumental support received by individuals. This differs from previous studies that examined the effect of social identification on one's willingness to give support for in-group members (Levine \& Thompson, 2004; Levine et al., 2005). For example, although team personnel may be motivated to give instrumental support to highly identified spectators, it is unlikely that those spectators receive more aid from the team because (a) the informal nature of team identification would make it difficult for the personnel to recognize individuals constituting highly identified in-group members and (b) the disaster situation would require the team to help everyone in need.

Finally, the examination of the correlation coefficients reveals that postdisaster community cohesion correlated more strongly with emotional support $(r=.49)$ than with instrumental support $(r=.29)$. This finding is consistent with past studies showing that the two types of social support differently contribute to well-being (Adams et al., 1996; Kaufmann \& Beehr, 1989). Relatedly, Nadler, Halabi, Harapz-Gorodeisky, and Ben-David (2010) explained that social support facilitates a receiver's well-being if the receiver interprets it as an indication of caring from a giver, but may not produce the same benefit if it is viewed as an indication of relative power relations between the giver and the receiver. In the current research context, the giving of tangible aid through instrumental support may be perceived as an obligation by the team to spectators residing in the community, while the emotional support, which entails the provision of intangible benefits, could be seen as a sign of caring from the team.

\section{Limitations and Directions for Future Research}


Limitations of this research as well as ideas for future research should be acknowledged. First, although the two limitations associated with a cross-sectional survey design, CMV and reversed mediation, were addressed through statistical analyses, the use of this design does not allow a causal relationship between team identification, emotional support, and social well-being to be inferred. The context of studying natural disasters limits the implementation of experimental designs, and future studies would gain further insight into the causal relationship by supplementing the current findings with in-depth qualitative data describing study participants' accounts of causation between these variables. Second, given that this research was conducted in a single culture, cross-cultural studies are needed to provide additional evidence for the relationship between team identification and well-being and the mediation of emotional support. Finally, future research should consider examining the positive psychological consequences of team identification in man-made disasters, such as military conflict and terrorisms, to test whether team identification would function differently in such situations when compared to the current examination of a natural disaster. 


\section{References}

Adams, G. A., King, L. A., \& King, D. W. (1996). Relationships of job and family involvement, family social support, and work-family conflict with job and life satisfaction. Journal of Applied Psychology, 81, 411-420.

Ahn, T., Suh, Y., Lee, J., \& Pedersen, P. M. (2012). Sport fans and their teams' redesigned logos: An examination of the moderating effect of team identification on attitude and purchase intention of team-logoed merchandise. Journal of Sport Management, 27, 1123.

Ai, A. L., Plummer, C., Heo, G., Lemieux, C. M., Simon, C. E., Taylor, P., \& Copeland, V. C. (2011). Racial identity-related differential attributions of inadequate responses to Hurricane Katrina: A social identity perspective. Race and Social Problems, 3, 13-24.

Ashforth, B.E., \& Mael, F. (1989). Social identity theory and the organization. Academy of Management Review, 14, 20-39.

Bergami, M., \& Bagozzi, R.P. (2000). Self-categorization, affective commitment and group selfesteem as distinct aspects of social identity in the organization. British Journal of Social Psychology, 39, 555-577.

Bergkvist, L., \& Rossiter, J. R. (2007). The predictive validity of multiple-item versus singleitem measures of the same constructs. Journal of Marketing Research, 44, 175-184.

Branscombe, N. R., Schmitt, M. T., \& Harvey, R. D. (1999). Perceiving pervasive discrimination among African Americans: Implications for group identification and well-being. Journal of Personality and Social Psychology, 77, 135-149.

Branscombe, N.R., \& Wann, D.L. (1991). The positive social and self concept consequences of sports team identification, Journal of Sport \& Social Issues, 15, 115-127. 
Breslow, L. (1972). A quantitative approach to the World Health Organization definition of health: Physical, mental and social well-being. International Journal of Epidemiology, 1, $347-355$.

Buckner, J. C. (1988). The development of an instrument to measure neighborhood cohesion. American Journal of Community Psychology, 16, 771-791.

Carver, C. S., Scheier, M. F., \& Weintraub, J. K. (1989). Assessing coping strategies: A theoretically based approach. Journal of Personality and Social Psychology, 56, 267-283.

Cox, R. S., \& Perry, K. M. E. (2011). Like a fish out of water: Reconsidering disaster recovery and the role of place and social capital in community disaster resilience. American Journal of Community Psychology, 48, 395-411.

Cruwys, T., Haslam, S. A., Dingle, G. A., Haslam, C., \& Jetten, J. (2014). Depression and social identity: An integrative review. Personality and Social Psychology Review. Advance online publication.

Dimmock, J. A., Grove, J. R., \& Eklund, R. C. (2005). Reconceptualizing team identification: New dimensions and their relationship to intergroup bias. Group Dynamics: Theory, Research, and Practice, 9, 75-86.

Drury, J., Cocking, C., \& Reicher, S. (2009). The nature of collective resilience: Survivor reactions to the 2005 London bombings. International Journal of Mass Emergencies and Disasters, 27(1), 66-95.

Folkman, S., Lazarus, R. S., Gruen, R. J., \& DeLongis, A. (1986). Appraisal, coping, health status, and psychological symptoms. Journal of Personality and Social Psychology, 50, 571-579. 
Fornell, C., \& Larcker, D. (1981). Evaluating structural equation models with unobservable variables and measurement error. Journal of Marketing Research, 18(1), 39-50.

Gleibs, I. H., Haslam, C., Haslam, S. A., \& Jones, J. M. (2011). Water clubs in residential care: Is it the water or the club that enhances health and well-being? Psychology \& Health, 26, $1361-1377$.

Guha-Sapir, D., Vos, F., Below, R., \& Ponserre, S. (2012). Annual disaster statistical review 2011: The numbers and trends. Brussels: CRED.

Hair, J.F., Anderson, R.E., Tatham, R.L., \& Black, W.C. (1998). Multivariate data analysis (5th ed.). Upper Saddle River, NJ: Pearson Education.

Haslam, S. A., Jetten, J., Postmes, T., \& Haslam, C. (2009). Social identity, health and wellbeing: An emerging agenda for applied psychology. Applied Psychology: An International Review, 58, 1-23.

Haslam, S. A., O'Brien, A., Jetten, J., Vormedal, K., \& Penna, S. (2005). Taking the strain: Social identity, social support, and the experience of stress. British Journal of Social Psychology, 44, 355-370.

Haslam, S. A., \& Reicher, S. (2006). Stressing the group: social identity and the unfolding dynamics of responses to stress. Journal of Applied Psychology, 91, 1037-1052.

Holt, D. B. (1995). How consumers consume: A typology of consumption practices. Journal of Consumer Research, 22, 1-16.

Hunt, K. A., Bristol, T., \& Bashaw, R. E. (1999). A conceptual approach to classifying sports fans. Journal of Services Marketing, 13, 439-452.

Inoue, Y., \& Havard, C.T. (2014). Sport and disaster relief: A content analysis. Manuscript submitted for publication. 
J. League. (2012a). Higashi nihon daishinsai kanren katsudou chousa houkokusyo [A report on disaster relief activities for the Great East Japan Earthquake]. Tokyo, Japan: J. League.

J. League. (2012b). J. League fan survey 2012 summary report. Tokyo, Japan: J. League.

Kaniasty, K. (2012). Predicting social psychological well-being following trauma: The role of postdisaster social support. Psychological Trauma: Theory, Research, Practice, and Policy, 4, 22-33.

Kaniasty, K., \& Norris, F. H. (2000). Help-seeking comfort and receiving social support: The role of ethnicity and context of need. American Journal of Community Psychology, 28, $545-581$

Kaufmann, G. M., \& Beehr, T. A. (1989). Occupational stressors, individual strains, and social supports among police officers. Human Relations, 42, 185-197

Kellezi, B., Reicher, S., \& Cassidy, C. (2009). Surviving the Kosovo conflict: A study of social identity, appraisal of extreme events, and mental well-being. Applied Psychology: An International Review, 58, 59-83.

Keyes, C. L. M. (1998). Social well-being. Social Psychology Quarterly, 61, 121-140.

Keyes, C. L. M., \& Lopez, S. L. (2002). Toward a science of mental health: Positive direction in diagnosis and interventions. In C. R. Snyder, S Lopez (Eds), The Handbook of Positive Psychology (pp. 45-59), New York: Oxford University Press.

Kwon, H. H., Trail, G., \& James, J. D. (2007). The mediating role of perceived value: Team identification and purchase intention of team-licensed apparel. Journal of Sport Management, 21, 540-554.

Leach, C. W., van Zomeren, M., Zebel, S., Vliek, M. L., Pennekamp, S. F., Doosje, B., ... \& Spears, R. (2008). Group-level self-definition and self-investment: A hierarchical 
(multicomponent) model of in-group identification. Journal of Personality and Social Psychology, 95, 144-165.

Levine, M., Prosser, A., Evans, D., \& Reicher, S. (2005). Identity and emergency intervention: How social group membership and inclusiveness of group boundaries shape helping behavior. Personality and Social Psychology Bulletin, 31, 443-453.

Levine, M., \& Thompson, K. (2004). Identity, place, and bystander intervention: Social categories and helping after natural disasters. The Journal of Social Psychology, 144, 229-245.

Lindell, M. K., \& Whitney, D. J. (2001). Accounting for common method variance in crosssectional research designs. Journal of Applied Psychology, 86, 114-121.

Mael, F., \& Ashforth, B.E. (1992). Alumni and their alma mater: A partial test of the reformulated model of organizational identification. Journal of Organizational Behavior, $13,103-123$.

Mael, F. A., \& Ashforth, B. E. (2001). Identification in work, war, sports, and religion: Contrasting the benefits and risks. Journal for the Theory of Social Behaviour, 31, 197222.

Markus, F. (2013, March 9). Two years on, new psychological stresses emerge amongst survivors of Japan's triple disaster. Retrieved from https://www.ifrc.org/en/news-andmedia/news-stories/asia-pacific/japan/two-years-on-new-psychological-stresses-emergeamongst-survivors-of-japans-triple-disaster-61021/

McNamara, N., Stevenson, C., \& Muldoon, O. T. (2013). Community identity as resource and context: A mixed method investigation of coping and collective action in a disadvantaged community. European Journal of Social Psychology, 43, 393-403. 


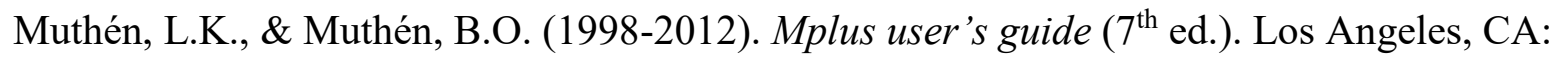
Muthén \& Muthén.

Nadler, A., Halabi, S., Harapz-Gorodeisky, G., \& Ben-David, Y. (2010). Helping relations as status relations. In M. Mikulincer \& P. R. Shaver. (Eds.), Prosocial motives, emotions, and behavior: The better angels of our nature (pp. 181-200). Washington, DC: American Psychological Association.

Norris, F. H., \& Kaniasty, K. (1996). Received and perceived social support in times of stress: A test of the social support deterioration deterrence model. Journal of Personality and Social Psychology, 71, 498-511.

Norris, F. H., Murphy, A. D., Kaniasty, K., Perilla, J. L., \& Ortis, D. C. (2001). Postdisaster social support in the United States and Mexico: Conceptual and contextual considerations. Hispanic Journal of Behavioral Sciences, 23, 469-497.

Outten, H. R., Schmitt, M. T., Garcia, D. M., \& Branscombe, N. R. (2009). Coping options: Missing links between minority group identification and psychological well-being. Applied Psychology: An International Review, 58, 146-170.

Preacher, K. J., \& Hayes, A. F. (2008). Asymptotic and resampling strategies for assessing and comparing indirect effects in multiple mediator models. Behavior Research Methods, 40, 879-891.

Rossiter, J. R. (2002). The C-OAR-SE procedure for scale development in marketing. International Journal of Research in Marketing, 19, 305-335.

Rubin, M., \& Hewstone, M. (1998). Social identity theory's self-esteem hypothesis: A review and some suggestions for clarification. Personality and Social Psychology Review, 2, 4062. 
Sutton, W. A., McDonald, M. A., Mime, G. R., \& Cimperman, J. (1997). Creating and fostering fan identification in professional sports. Sport Marketing Quarterly, 6(1), 15-22.

Tajfel, H., \& Turner, J.C. (1979). An integrative theory of intergroup conflict. In W.G. Austin \& S. Worchel (Eds.), The social psychology of intergroup relations (pp. 33-47). Monterey, CA: Brooks/Cole.

Tajfel, H., \& Turner, J.C. (1985). The social identity theory of intergroup behavior. In S. Worchel, W.G. Austin. (Eds), Psychology of Intergroup Relations (2 ${ }^{\text {nd }}$ ed.) (pp.7-24), Chicago, IL: Nelson-Hall.

Trail, G., \& James, J. (2001). The motivation scale for sport consumption: Assessment of the scale's psychometric properties. Journal of Sport Behavior, 24, 108-127.

Turner, J.C., Oakes, P.J., Haslam, S.A., \& McGarty, C.A. (1994). Self and collective: Cognition and social context. Personality and Social Psychology Bulletin, 20, 454-463.

Wakefield, K. L. (1995). The pervasive effects of social influence on sporting event attendance. Journal of Sport \& Social Issues, 19, 335-351.

Wann, D. L. (2006). Understanding the positive social psychological benefits of sport team identification: The team identification-social psychological health model. Group Dynamics: Theory, Research, and Practice, 10, 272-296.

Wann, D. L., Dimmock, J. A., \& Grove, J. R. (2003). Generalizing the team identificationpsychological health model to a different sport and culture: The case of Australian rules football. Group Dynamics: Theory, Research, and Practice, 7, 289-296.

Wann, D. L., Melnick, M. J., Russell, G. W., \& Pease, D. G. (2001). Sport fans: The psychology and social impact of spectators. New York: Routledge Press. 
Wann, D. L., Waddill, P. J., Polk, J., \& Weaver, S. (2011). The team identification-social psychological health model: Sport fans gaining connections to others via sport team identification. Group Dynamics: Theory, Research, and Practice, 15, 75-89.

Wu, S., Tsai, C.D., \& Hung, C. (2012). Toward team or player? How trust, vicarious achievement motive, and identification affect fan loyalty. Journal of Sport Management, $26,177-191$

Yoshida, M., Gordon, B., Nakazawa, M., \& Biscaia, R. (2014). Conceptualization and measurement of fan engagement: Empirical evidence from a professional sport context. Journal of Sport Management, 28, 399-417. 


\section{Footnotes}

${ }^{1}$ Questionnaires were distributed in the stands prior to the start of the game. To collect data as systematically as possible, the authors used a mixture of convenience and proportionate sampling that was stratified by both age and gender. Before distributing the questionnaires, trained surveyors observed an assigned block of the stands to estimate the percentage of those attending based on gender and age. Each surveyor was responsible for distributing twenty selfadministered questionnaires according to the estimated percentages based on gender and age.

${ }^{2}$ The CMV adjustment yielded a partial correlation of $.11(t=3.16)$ for the correlation between Team identification and postdisaster social well-being, $.23(t=7.10)$ for the correlation between $\mathrm{C}-\mathrm{C}$ - identification and emotional support, $.25(t=7.79)$ for the correlation between instrumental support and postdisaster social well-being, and $.46(t=15.59)$ for the correlation between emotional support and postdisaster social well-being. As a sensitivity analysis, the 75 th percentile point of the correlation used for the CMV estimate was computed $(r=.09)$, and used in the CMV adjustment (Lindell \& Whitney, 2001). This procedure still provided significant results for all of the partial correlations: $.07(t=2.02, p<.05)$ between Team identification and postdisaster social well-being, $.20(t=6.10, p<.01)$ between Team identification and emotional support, $.22(t=6.77, p<.01)$ between instrumental support and postdisaster social well-being, and $.44(t=14.64, p<.01)$ between emotional support and postdisaster social well-being, further rejecting that the current results were accounted for by CMV. 
Table 1

Descriptive Statistics and Correlations

\begin{tabular}{|c|c|c|c|c|c|c|c|c|c|c|c|c|c|c|}
\hline Variable & $M$ & $S D$ & 1 & 2 & 3 & 4 & 5 & 6 & 7 & 8 & 9 & 10 & 11 & 12 \\
\hline 1. Sendai ${ }^{\mathrm{a}}$ & 0.35 & 0.48 & - & & & & & & & & & & & \\
\hline 2. Kashima $^{\mathrm{b}}$ & 0.28 & 0.45 & $-.46^{* *}$ & - & & & & & & & & & & \\
\hline 3. Gender ${ }^{\mathrm{c}}$ & 0.61 & 0.49 & $-.07^{*}$ & -.02 & - & & & & & & & & & \\
\hline 4. Age & 39.39 & 13.99 & -.06 & -.02 & .05 & - & & & & & & & & \\
\hline 5. Spectator experience & 9.16 & 5.76 & -.05 & $.34^{* *}$ & $.17^{* *}$ & $.24^{* *}$ & - & & & & & & & \\
\hline 6. Life threat & 4.03 & 1.00 & $.10^{* *}$ & $.07^{*}$ & $-.11^{* *}$ & .01 & .05 & - & & & & & & \\
\hline 7. Material losses & 2.78 & 1.23 & $.31^{* *}$ & .05 & -.04 & .01 & $.10^{* *}$ & $.42^{* *}$ & - & & & & & \\
\hline 8. Social support from other sources & 2.70 & 1.37 & $.33^{* *}$ & $-.08^{*}$ & .03 & $-.18^{* *}$ & -.01 & $.16^{* *}$ & $.30^{* *}$ & - & & & & \\
\hline 9. Team identification & 4.35 & 0.80 & .01 & .03 & $.10^{* *}$ & $.13^{* *}$ & $.25^{* *}$ & .05 & $.07^{*}$ & $.09^{* *}$ & - & & & \\
\hline 10. Instrumental support & 2.05 & 1.29 & $.15^{* *}$ & $-.11^{* *}$ & $.08^{*}$ & $-.24^{* *}$ & $-.10^{* *}$ & .06 & $.19^{* *}$ & $.58^{* *}$ & -.01 & - & & \\
\hline 11. Emotional support & 3.54 & 1.02 & $.33^{* *}$ & $-.10^{* *}$ & -.05 & $-.07^{*}$ & .02 & $.17^{* *}$ & $.23^{* *}$ & $.47^{* *}$ & $.27^{* *}$ & $.33^{* *}$ & - & \\
\hline 12. Postdisaster community cohesion & 3.73 & 0.72 & $.23^{* *}$ & $-.18^{* *}$ & .02 & .01 & $-.07^{*}$ & $.15^{* *}$ & $.13^{* *}$ & $.32^{* *}$ & $.15^{* *}$ & $.29^{* *}$ & $.49^{* *}$ & - \\
\hline
\end{tabular}

Note. $N=893$.

${ }^{\mathrm{a}} 1=$ data from a Vegalta Sendai game and $0=$ otherwise. $^{\mathrm{b}} 1=$ data from a Kashima Antlers game and $0=$ otherwise. ${ }^{\mathrm{c}} 1=$ male and $0=$ female. ${ }^{*} p<.05{ }^{* *} p<.01$. 
Table 2

Bootstrap Test of the Indirect Effect of Team Identification through Instrumental Support and Emotional Support

\begin{tabular}{lrrrrr}
\hline & & & \multicolumn{2}{c}{ Bootstrapping $(99 \% \mathrm{CI})$} \\
\cline { 5 - 6 } \multicolumn{1}{c}{ Mediator } & Effect & $S E$ & \multicolumn{2}{c}{ Lower } & Upper \\
\hline Instrumental Support & -0.01 & 0.00 & -0.02 & 0.00 \\
Emotional Support & 0.07 & 0.01 & 0.04 & 0.11 \\
TOTAL & 0.07 & 0.01 & 0.04 & 0.11 \\
\hline
\end{tabular}

Note. $N=893$. Unstandardized values are shown. $S E=$ standard error. $\mathrm{CI}=$ confidence interval. 


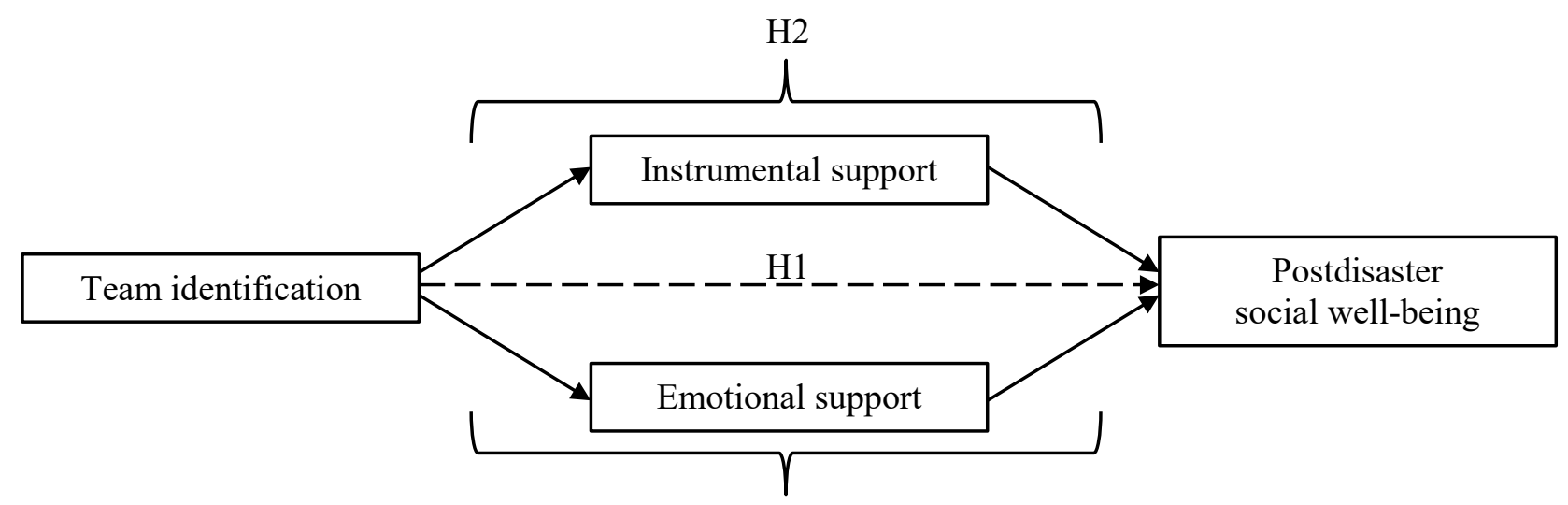

Figure 1. Research model. $\mathrm{H}=$ Hypothesis . 


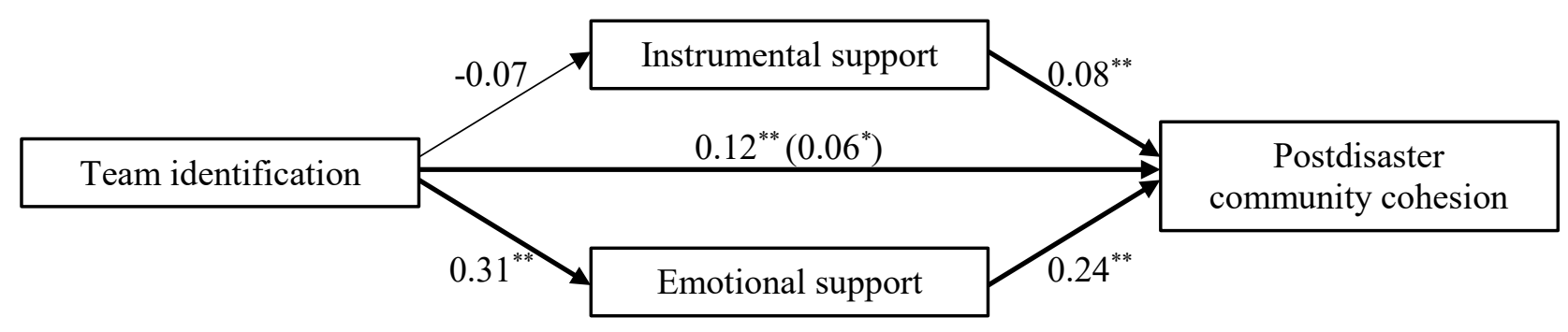

Figure 2. Results of regression analysis with Preacher and Hayes's (2008) bootstrapping approach. The control variables are excluded from the figure. Postdisaster community cohesion is included as an indicator of postdisaster social well-being. The bolded arrows indicate significant results. The value in the parentheses represents the direct effect of team identification on postdisaster community cohesion when its indirect effects through instrumental and emotional support are taken into account. Unstandardized values are shown. ${ }^{*} p<.05 .{ }^{* *} p<.01$ 